\title{
Spontaneous rupture of a saphenous vein graft
}

\author{
Patrick Davey, David Gwilt, Colin Forfar
}

\begin{abstract}
Summary
We present a case of spontaneous rupture of a right coronary bypass vein graft in a 57-year-old woman 10 years after coronary by-pass surgery. Although rare, this diagnosis should be considered in such patients presenting with appropriate symptoms.
\end{abstract}

Keywords: coronary artery bypass graft; false aneurysm; saphenous vein graft

Coronary artery rupture as a consequence of interventional procedures is well described both for native coronary vessels and for bypass grafts. ${ }^{1}$ Spontaneous rupture in the absence of intervention is rare, though described for native vessels. $^{23}$ Spontaneous rupture of a bypass graft is an even rarer occurrence.

\section{Case report}

A 57-year-old woman presented with sudden onset of chest pain, described by her as 'explosive', and so severe as to 'knock her to the ground'. The pain was in the anterior chest, radiated through to the back, and was exacerbated by deep respiration and by movement. She felt nauseated and was breathless. Moderately intense pain continued until admission to hospital 4 hours later, by which time she had experienced some minor haemoptysis. She had undergone coronary surgery 15 years earlier, with vein grafts to the left anterior descending artery and diagonal branch; 10 years ago the vein grafts were occluded, and she underwent further coronary surgery, with grafts to the left anterior descending artery (left internal mammary artery) and the right coronary artery (saphenous vein graft). Two years prior to the current admission, angiography demonstrated impaired left ventricular function, with an ejection fraction of $45 \%$, occluded left anterior descending artery, with a good distal internal mammary artery graft, severe native circumflex disease, and an occluded native right coronary with the distal vessel supplied by an ectatic bypass vein graft, measuring up to $2 \mathrm{~cm}$ in diameter (figure 1). Medical management was pursued.

Examination showed her to be in mild distress, warm, heart rate 90 beats/min, with no signs of heart failure and normal cardiac auscultation. Saturation on finger plethysmography was $76 \%$. Chest X-ray showed cardiomegaly with clear lung fields. Electrocardiography (ECG) showed no new changes.

The most likely diagnosis was felt to be a pulmonary embolus, though aortic dissection was also considered. Computed tomography (CT) scan revealed a unremarkable aorta, with an

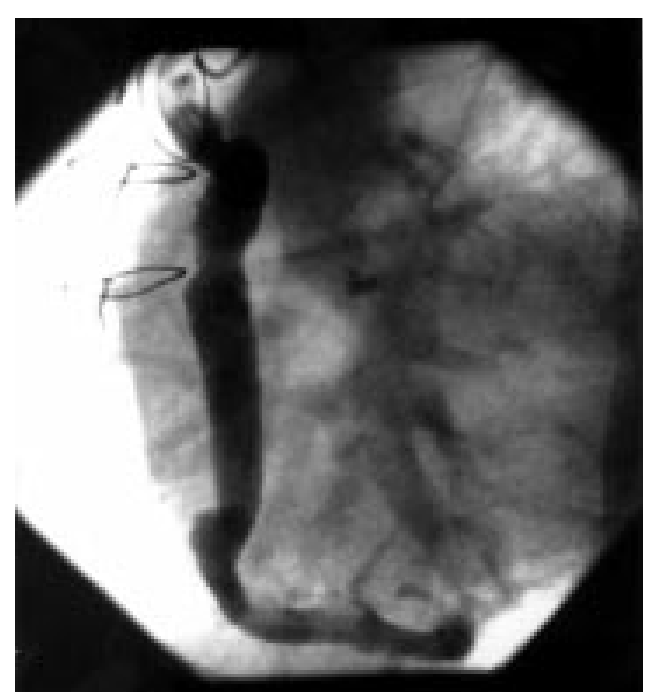

Figure 1 Angiography of the venous bypass graft to the right coronary artery. This figure shows a 6 French diagnostic coronary catheter intubating the ectatic right coronary graft.

abnormal structure lying behind the heart. Transthoracic echocardiography (TTE) revealed a small $1 \times 2 \mathrm{~cm}$ fluid-filled structure lying behind the left atrium. Twelve hours later repeat TTE showed that this structure had enlarged dramatically, resulting in severe compression of the left atrium. Transoesophageal echocardiography (TOE, figure 2) showed a large mass behind and to the right side of the heart. This structure had a thick rim, with spontaneous contract echo. Laterally there was a thick rimmed structure divided by a thick septum. Repeat CT scan of the chest (figure 2) showed that contrast leaked into the posterior structure. At urgent thoracotomy, a large false aneurysm of the right coronary saphenous by-pass graft was found, with extensive extravasation of blood into the surrounding tissues. Haemostasis was achieved, but it was not possible to wean her from bypass, and she died.

\section{Discussion}

Late rupture of a coronary bypass graft seems very rare. In this case, rupture led to extrinsic compression of the left atrium, and subsequent left heart failure, hypoxaemia, haemoptysis and death. Of particular interest was the difficulty in establishing the correct diagnosis, which was in part due to its rarity. At presentation, the sudden onset of pleuritic chest pain, with hypoxaemia and haemoptysis led to an initial diagnosis of pulmonary embolism, though common forms of vascular catastrophe, including aortic dissection, were considered. Initial 
Figure 2 Top: TOE The orientation of the probe is such that structures on the right side of the heart are shown on the left side of this photo, and those behind the heart at the top of the photo. A large thick walled mass is seen immediately adjacent to the probe, extending anteriorly for up to $5 \mathrm{~cm}$, and virtually obliterating the left atrium. The ectatic vein graft is seen, together with its false aneurysm, to the right of the heart. Below: Thoracic CT scan, with contrast. This CT scan demonstrates the contrast-filled right coronary vein graft and, posterior and medial to the graft, the crescent-shaped false aneurysm. There is a $5 x$ $5 \mathrm{~cm}$ mass of extravasated blood behind the heart, which is lightly stained with contrast
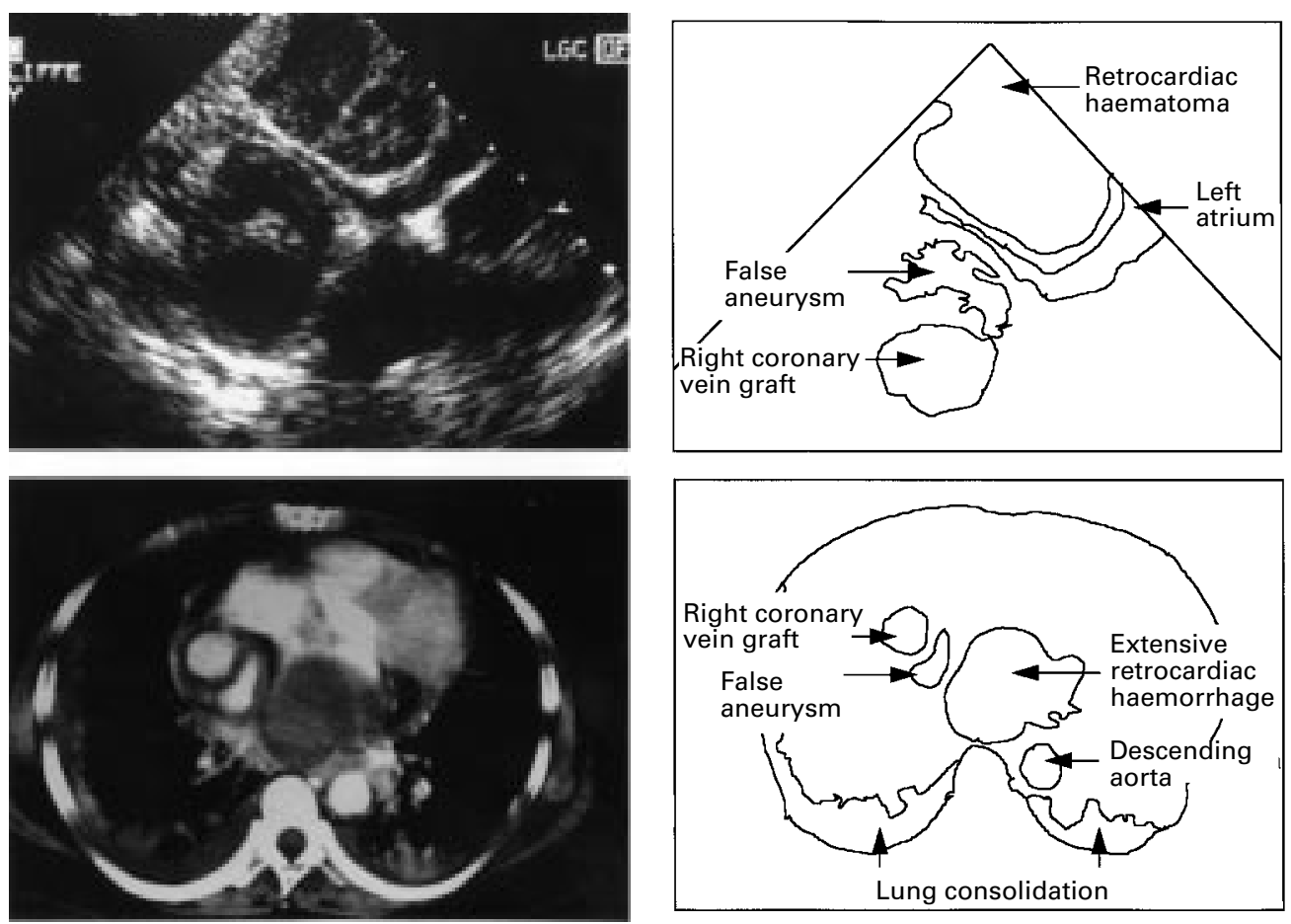

investigations were inconclusive, and it was not until 12 hours later, after further bleeding into the mediastinum had occurred, that investigations revealed the true nature of the problem. Diagnosis was established by demonstrating blood in the mediastinum on CT scanning as well as a false aneursym of the coronary graft. In other case reports diagnosis has usually been suggested by CT scanning, though TOE has been used, and diagnosis has been confirmed either by coronary angiography or at surgery. ${ }^{4}$ The usual treatment is surgery to tie off both ends of the ruptured graft, with or without the application of further grafts. In patients unfit for surgery trans-catheter embolisation of the false aneursyms may be a viable alternative. ${ }^{4}$

Rupture of vascular structures depends on several factors, including wall stress, which in turn will depend on blood pressure, and the thickness of the vessel wall, as well as the size of the vessel, according to the law of Laplace. An important factor in the rupture of this bypass graft may have been the antecedent aneurysmal dilatation. Large numbers of coronary operations use veins as conduits and, as veins are thin-walled structures, and as aneursymal dilation of vein grafts is not infrequent, one might expect to see spontaneous rupture more commonly. Current data suggest, however, that spontaneous rupture is unusual. ${ }^{5-8}$ It is possible

1 Drummer E, Furey K, Hollman J. Rupture of a saphenous vein bypass graft during coronary angioplasty. $\mathrm{Br}$ Heart $\mathcal{F}$ 1987;58:78-81

2 Atay Y, Yagdi T, Turkoglu C, Altintig A, Buket S. Spontaneous dissection of the left main coronary artery: a case report and review of the literature. F Card Surg 1996;11:371-5.

3 Kearney P, Singh H, Hutter J, Khan S, Lee G, Lucey J. Spontaneous coronary artery dissection: a report of three cases and review of the literature. Postgrad Med $f$ 1993;69:940-5.

4 Le Breton H, Pavin D, Langanay T, et al. Aneursyms and pseudoaneurysms of saphenous artery bypass grafts. Heart 1998;79:505-8.

\section{Learning points}

- spontaneous rupture of a saphenous bypass vein graft is rare, but does occur

- the most important aspect of diagnosis is awareness of this late complication of coronary artery bypass surgery

- diagnosis can be made by CT, MRI, TOE, or coronary angiography by trans-catheter embolisation

that the true incidence is underestimated, as many patients with previous coronary surgery who present with further chest pain may be thought to have further myocardial ischaemia, particularly if there are new ECG changes. Death in these circumstances is rarely followed by a post mortem, and thus the true diagnosis may not be established. However in subjects presenting with symptoms suggestive of a vascular catastrophe, this diagnosis is worth consideration. Furthermore, presentation can be atypical, and therefore the diagnosis should onary surgery with saphenous vein bypass grafts who present with atypical chest pain, superior vena caval obstruction, or mediastinal masses. $^{4}$

5 Shapeero LG, Guthaner DF, Swerdlow CD, Wexler L. Rupture of a coronary bypass graft aneurysm: CT evaluation and coil occlusion therapy. AfR 1983;141:1060-2.

6 Werthman PE, Sutter FP, Flicker S, Goldman SM. Spontaneous, late rupture of an aortocoronary saphenous vein graft. Ann Thorac Surg 1991;51:664-6.

7 Murphy JP, Jr, Shabb B, Nishikawa A, Adams PR, Walker aneurysm. Am f Cardiol 1986;58:555-7.

8 Kallis P, Keogh BE, Davies MJ. Pseudoaneurysm of case report and literature review. Br Heart f 1993;70:189-92.
- haemostasis can be achieved either by surgery or be considered in all patients who have had corWE. Rupture of an aortocoronary saphenous vein graft aortocoronary vein graft secondary to late venous rupture: 